\title{
Studies on the Antioxidant and Antimicrobial Properties of Rosemary (Rosemarinus officinalis) and Oregano (Origanum vulgare) Extracts
}

\author{
M. Kumuda ${ }^{1}$, K. Dhanapal ${ }^{1 *}$, K. Sravani ${ }^{1}$, K. Madhavi ${ }^{2}$, \\ Faisal Rashid Sofi ${ }^{1}$ and G. Praveen Kumar ${ }^{1}$ \\ ${ }^{1}$ Department of Fish Processing Technology, ${ }^{2}$ Department of Aquatic Environment Management, \\ College of Fishery Science, Muthukur, Nellore District, Andhra Pradesh, India \\ *Corresponding author
}

\section{A B S T R A C T}

Antioxidant and antimicrobial compounds in food play an important role in protecting health. These are also widely used as additives in fat, oils and in food processing to prevent or delay spoilage of foods. Attention towards the utilization of spices and some herbs as source of effective antioxidant and antimicrobial compounds has increased. In this study, the antioxidant and antibacterial properties of rosemary and oregano extracts were

Keywords

Rosemary, Oregano, BHT, Antioxidant and Antimicrobial.

Article Info Accepted: 23 October 2017 Available Online: 10 December 2017 compared with synthetic antioxidant like butylated hydroxyl toluene (BHT). Antioxidant properties of DPPH radical scavenging, ferric reducing power assay and metal chelating activity were assessed at different concentrations $100 \mathrm{ppm}$ to $500 \mathrm{ppm}(\mathrm{p}<0.05)$. DPPH radical scavenging activity of Rosemary and Oregano extracts were $77.37 \%$ and $62.86 \%$ at $100 \mathrm{ppm}$ respectively. Rosemary extract has shown highest ferric reducing activity at 500 $\mu \mathrm{g} / \mathrm{mL}$, which is almost equivalent to BHT at $200 \mathrm{mg} / \mathrm{L}$. Although both rosemary and oregano extracts were less efficient in metal chelating activity compared to synthetic metal chelator (EDTA), rosemary extract exhibited more chelating activity compared to oregano extract. Antibacterial properties of rosemary and oregano extracts were assessed using the disc diffusion assay based on mean diameter of inhibitory zone and minimum inhibitory dose. Rosemary and oregano extracts were potentially active against gram+ve bacteria viz., Staphylococcus aureus and Bacillus subtilis whereas, smaller zones of inhibition against gram-ve bacteria viz., Escherichia coli, Salmonella typhium and Pseudomonas fluorescens. Therefore, among these two extracts, rosemary extract shown better antioxidant and antimicrobial properties compared to the oregano extract suggesting its application in food industry.

\section{Introduction}

Phenolic compounds are commonly found in both edible and non-edible plants and they have been reported to contain multiple biological effects, including antioxidant and antimicrobial activity. The interest towards the utilization of crude extracts of herbs and other plant materials rich in phenolics increased in the food industry because they retard oxidative degradation of lipids thereby improving the quality and nutritional value of food. The importance of the antioxidant constituents of plant materials in the maintenance of health and protection from coronary heart disease and cancer is also raising interest among scientists, food manufacturers, and consumers as the trend of 
the future is moving toward functional food with specific health effects (Löliger, 1991).

The current increase in consumer's demand for natural antioxidants and antimicrobial compounds had forced companies and researchers to explore different ways to improve their market penetration by offering products with improvements in quality, freshness and food safety. One of the more fashionable trend consists of the development of innovative biopolymers obtained from agricultural commodities and/ or food-waste products. Plant extract of Rosemary (Rosemarinus officinalis) is one of the most effective spices widely used in food processing. It is the most important spices commercially available for use as an antioxidant and antimicrobial substance. The first use of an extract of rosemary leaves as an antioxidant was reported by Rac and Ostric (1955). The application of rosemary extracts in food had given a variety of results and those depend on the test model being used. Rosemary was considered as a lipid antioxidant, metal chelator and found to scavenge superoxide radicals. Rosemary used as a single or combined extracts, have antibacterial activities against Bacillus sps, Salmonella sps and also retard lipid oxidation in meat to improve their quality and nutritional value (Tironi et al., 2009).

Oregano (Origanum vulgare) is very often used as a spices and its flavour is very popular with consumers all over the world. Muchuweti et al., (2007) reported that oregano had the highest antioxidant activity by comparing different herbs and spices. In addition to this, oregano extract also contains phenolic carboxylic acids and glycosides having antioxidant, antimicrobial and effective superoxide anion radical scavengers (Nakatani, 2003). Oregano phenolics have significant antioxidant activity and are effective in the inhibition of all phases of the peroxidative process by neutralizing free radicals, blocking the oxidation catalysis by iron and interrupting the lipid radical chain reactions (Dornan et al., 2003). Primarily rosmarinic acid is the major phenolic component of oregano extract, which can prevent colour deterioration (Hernandez et al., 2009). The dried oregano had demonstrated in vitro antibacterial activity against a wide range of gram-positive and gram-negative microorganisms. Based on the previous studies on properties of rosemary and oregano extracts as discussed above, a study was conducted to study the effect of rosemary and oregano extracts and compare with the synthetic antioxidants. The study will help in reducing the usage of synthetic antioxidants by replacing with natural antioxidants and antimicrobial compounds to extend the shelf life of food products for safety and health.

\section{Materials and Methods}

Two plant varieties viz, Rosemary and Oregano were used for this study. The materials were collected from Mumbai hot \& spices at Chennai.

\section{Bacterial cultures}

Bacterial cultures, namely Staphylococcus aureus (NCIM 2079), Escherichia coli (NCIM 2688), Bacillus subtilis (NCIM 2063), Salmonella typhium (NCIM 2501) and Pseudomonas fluorescens (NCIM 2099) were used for the study

\section{Diphenyl-1-Picrylhydrazyl radical quenching activity (DPPH)}

The DPPH radical scavenging activity of rosemary and oregano at various concentrations was determined according to the method as described by Yen and $\mathrm{Wu}$ (1999). The radical scavenging activity of rosemary and oregano was compared with the 
standard compounds BHT at 200 ppm respectively. A known volume of $1.5 \mathrm{ml}$ of rosemary/oregano extract was added to $1.5 \mathrm{ml}$ of $0.1 \mathrm{mM}$ DPPH solution prepared in $99.5 \%$ ethanol and thoroughly mixed by using cyclomixer at high speed. The mixture was incubated in the dark at room temperature for $30 \mathrm{~min}$. After the incubation, the absorbance (Abs) was measured at $517 \mathrm{~nm}$ using spectrophotometer. The lower absorbance of the reaction mixture indicates higher free radical scavenging activity. DPPH radicalscavenging activity was calculated and expressed in terms of percentage of DPPH free radicals scavenged using the following formula;

DPPH radical scavenging activity $(\%)=1-\frac{\mathrm{Abs}_{\text {Sample }}}{\mathrm{Abs}_{\text {Control }}} \mathrm{X} 100$

\section{Ferric Reducing Antioxidant Power assay (FRAP)}

The ferric reducing antioxidant power of rosemary and oregano was measured to reduce ferric ions to ferrous ions as determined at different concentrations by the method of Oyaizu (1986). The ferric reducing antioxidant power of the extracts was compared with standard antioxidant BHT at $200 \mathrm{ppm}$. An aliquot of $1 \mathrm{ml}$ sample was taken and mixed with $2.5 \mathrm{ml}$ of $0.2 \mathrm{M}$ phosphate buffer (pH 6.6) and $2.5 \mathrm{ml}$ of $1 \%$ (w/v) potassium ferricyanide. The mixture was incubated at $50^{\circ} \mathrm{C}$ for $30 \mathrm{~min}$. After incubation, $2.5 \mathrm{ml}$ of $10 \% \quad(\mathrm{w} / \mathrm{v})$ trichloroacetic acid was added. Finally, $2.5 \mathrm{ml}$ of the solution from the mixture was drawn and mixed with $2.5 \mathrm{ml}$ of distilled water and $0.5 \mathrm{ml}$ of $0.1 \%(\mathrm{w} / \mathrm{v})$ ferric chloride solution. After a $10 \mathrm{~min}$ of reaction time, the absorbance of the resultant solutions was measured at $700 \mathrm{~nm}$ using spectrophotometer. Higher absorbance of the reaction mixture indicates higher reducing power.

\section{Metal chelating activity}

The chelating activity of rosemary and oregano at different concentration was measured by the method of Boyer and Mccleary (1987) and was compared with standard metal chelator EDTA at $1 \mathrm{mM}$. An aliquot of $4.7 \mathrm{ml}$ of sample with a concentration ranging from $0.5-3 \mathrm{mg} / \mathrm{L}$ was taken and mixed with $0.1 \mathrm{ml}$ of $2 \mathrm{mM} \mathrm{FeCl} 2$ and $0.2 \mathrm{ml}$ of $5 \mathrm{mM}$ ferrozine. The reaction mixture was allowed to stand for 20 min's at room temperature. The absorbance was then read at $562 \mathrm{~nm}$. The blank was prepared in the same manner except that distilled water was used instead of the sample. For the sample blanks at each concentration, $\mathrm{FeCl}_{2}$ solution was excluded and distilled water was used instead. The chelating activity after the sample blank subtraction was calculated as follows:

Metal chelating activity $(\%)=1-\frac{\mathrm{Abs}_{\text {Sample }}}{\mathrm{Abs}_{\text {blank }}} \times 100$

\section{Antimicrobial activity of Rosemary and Oregano by disc diffusion method}

The antibacterial test for rosemary and oregano were performed by the agar disc diffusion method (Bauer et al., 1966; Nair and Chanda, 2005). The rosemary and oregano was checked at a concentration of $5 \mathrm{mg} / \mathrm{ml}$, whereas, ampicillin at a concentration of 1 $\mathrm{mg} / \mathrm{L}$ was used as positive control. Bacterial strains were first grown on Muller Hinton medium for 18 to $24 \mathrm{~h}$ at $37^{\circ} \mathrm{C}$. A sterile 10 $\mathrm{mm}$ diameter filter disc impregnated with respective extracts and ampicillin were placed on the infusion agar seeded with bacteria. Then, Petri dishes were incubated at $37^{\circ} \mathrm{C}$ for 24 hours. The antibacterial activity was assessed by measuring the zone of growth inhibition surrounding the discs. All experiments were carried out in replicates. The antibacterial activity was expressed as the mean diameter of inhibition zone produced. 


\section{Results and Discussion}

\section{Antioxidant activity}

The antioxidant potential of plant products and pure compounds can be evaluated using numerous assays. The first step in these examinations is the screening of the potential activity by different in vitro tests. Each of these methods is based on one feature of the antioxidant activity, such as the ability of scavenging free radicals, the ferric reducing power assay, the chelating of metal ions. However, in order to get relevant data, a single method for testing antioxidant activities of plant products is not recommended due to their complex composition (Nuutila et al., 2003). Therefore, the antioxidant activity of the tested rosemary and oregano had been evaluated in a series of in vitro tests. Many natural plant extracts have been studied in relation to their antioxidant and antimicrobial properties (Bendini et al., 2002). Rosemary (Rosmarinus officinalis) and Oregano (Origanum vulgare) phenolics have multifunctional actions, it can act as a chelating agent, scavenge superoxide radical and can inhibit the lipid oxidation, neutralizing free radicals, blocking the peroxidation catalysis by iron and interrupting the lipid radical chain reactions (Dornan et al., 2003).

\section{Diphenyl-1 picrylhydrazyl radical scavenging activity}

DPPH is one of the most extensively used antioxidant assays for measurement of free radical scavenging activity. This method is based on the scavenging of DPPH through the addition of a radical species or an antioxidant that decolourizes the DPPH solution (Krishnaiah et al., 2011).

The DPPH radical scavenging activity of rosemary and oregano were seen at 100$500 \mathrm{mg} / \mathrm{L}$ and were compared with reference standard antioxidants BHT at concentration of $200 \mathrm{mg} / \mathrm{L}$ (Table 1). The activity of both the compounds decreased with increasing concentration $(\mathrm{p}<0.05)$. At the same concentration used, the descending orders of DPPH radical scavenging activity of the tested compounds were as follows: Rosemary $>$ Oregano.

Results suggest that BHT showed highest radical scavenging activity of $82.69 \%$, whereas rosemary and oregano showed radical scavenging activity of $77.37 \%$ and $62.56 \%$ at $100 \mathrm{mg} / \mathrm{L}$. It was observed that with the increase in concentration, the radical scavenging activities of both the extracts (rosemary and oregano) decreased. The present results were in agreement with the findings of Hendel et al., (2016) who reported that rosemary exhibited a high radical scavenging activity $(11.741 \pm 0.004 \mu \mathrm{g} / \mathrm{ml})$ close to those of the tested synthetic antioxidants viz., ascorbic acid (3.036 \pm 0.217 $\mu \mathrm{g} / \mathrm{ml})$, BHA $(7.492 \pm 0.057 \mu \mathrm{g} / \mathrm{ml})$ and BHT $(21.211 \pm 2.593 \mu \mathrm{g} / \mathrm{ml})$.

Lugemwa et al., (2013) studied the DPPH radical scavenging activities of several herbs and observed that oregano and rosemary extracts have shown an LC 50 value of 592.5 and $414.2 \mathrm{mg}$ of phenol/L respectively. Similar results were observed by Khanum et al., (2011) who reported that oregano exhibited maximum radical scavenging activity of $88.2 \%$ and $82.3 \%$ for aqueous and ethanolic extracts at $50 \mathrm{ppm}$ concentration respectively.

\section{Ferric reducing antioxidant power of Rosemary and Oregano extracts}

Ferric reducing antioxidant power assay is based on the reaction, which measures reduction of ferric $\left(\mathrm{Fe}^{3+}\right)$ 2, 4, 6 tripyridyl-5triazine (TPTZ) to a coloured ferrous $\left(\mathrm{Fe}^{2+}\right)$ TPTZ product. 
Fig.1 Antimicrobial activity of the rosemary and oregano extracts against different bacteria

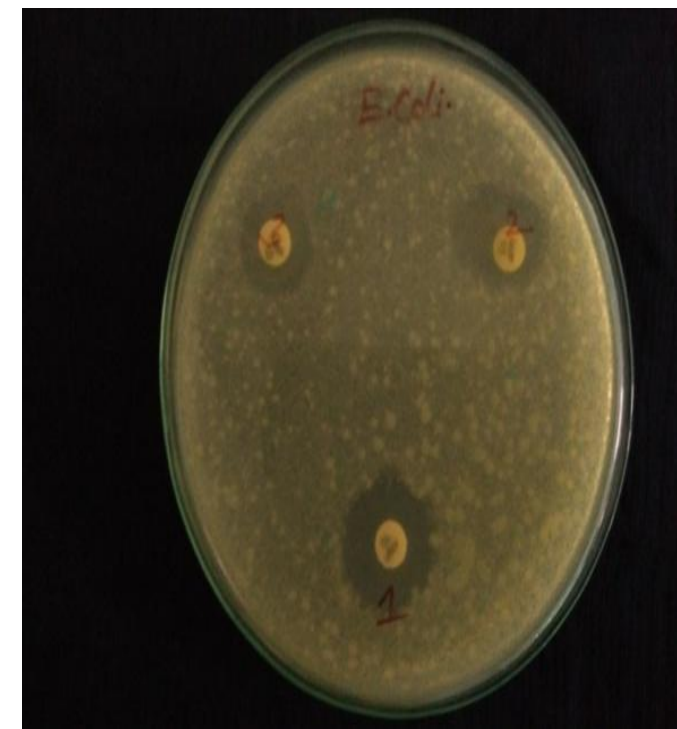

A

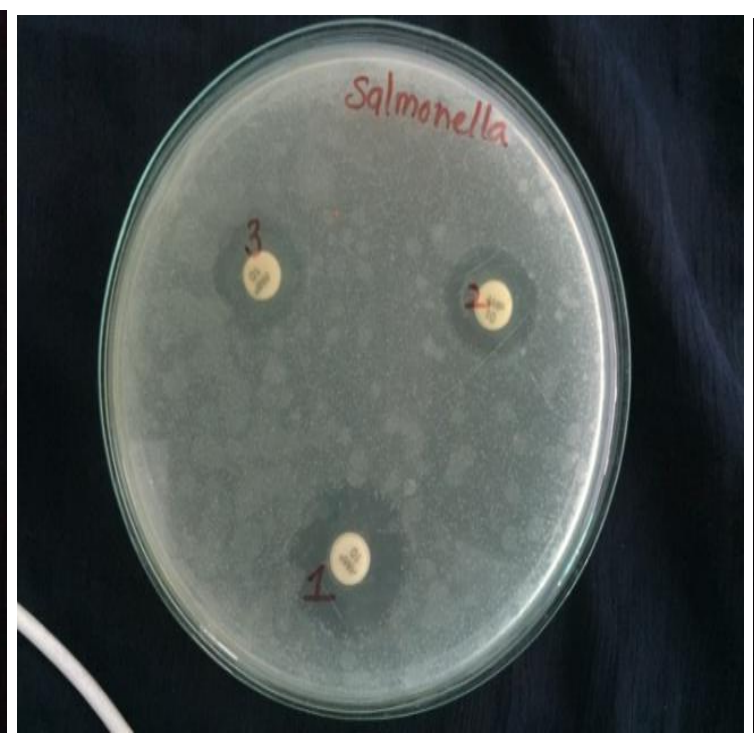

$\mathrm{B}$
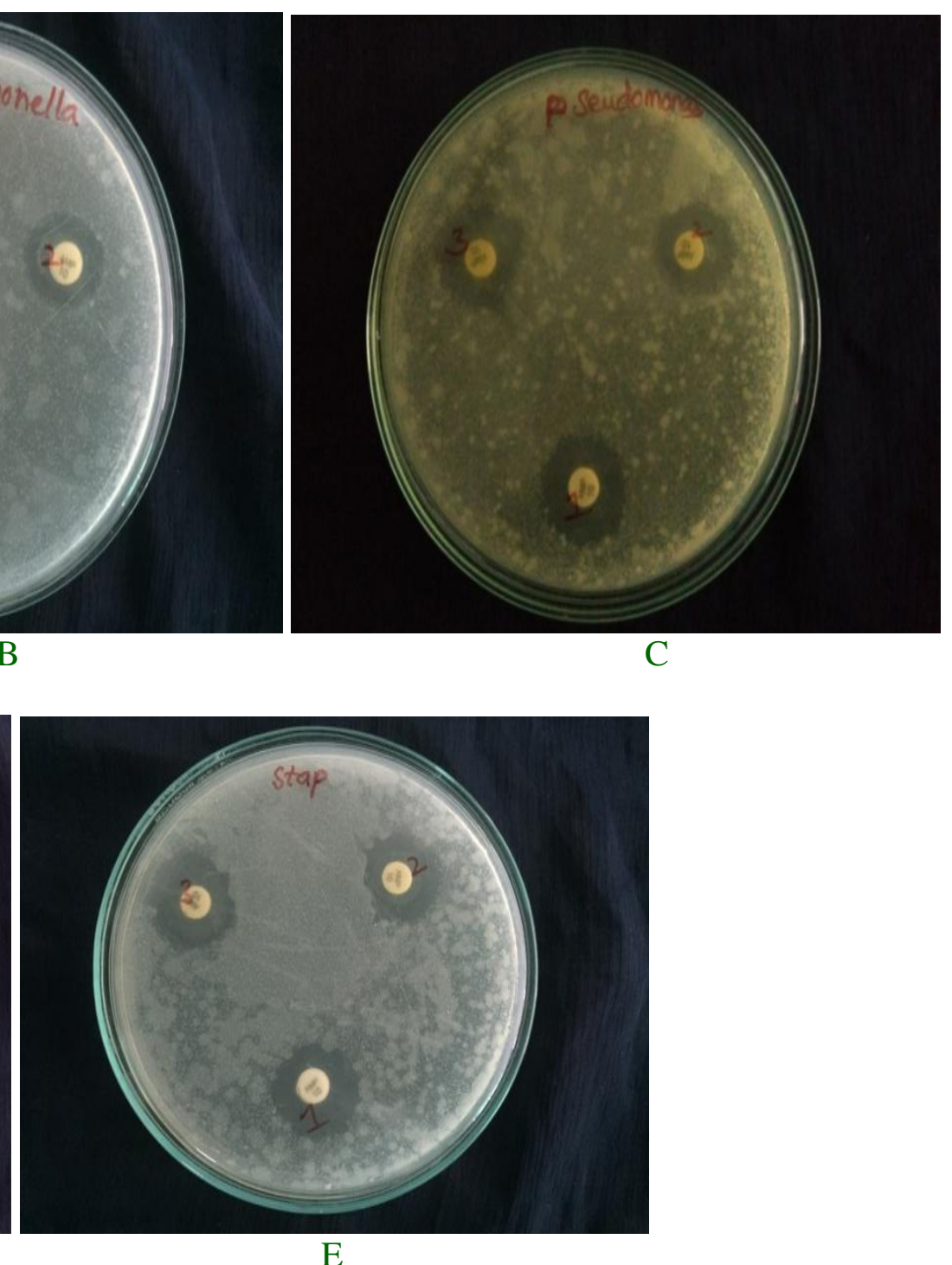

E

Note: A. Escherichia coli; B. Salmonella typhi; C. Pseudomonas fluorescens; D. Bacillus subtilis; E. Staphylococcus aureus 
Table.1 Antioxidant activity of Rosemary and Oregano extracts

\begin{tabular}{|c|l|l|l|l|l|l|}
\hline \multirow{2}{*}{$\begin{array}{c}\text { Antioxidant } \\
\text { activity }\end{array}$} & \multicolumn{2}{|c|}{ DPPH } & \multicolumn{2}{c|}{ FRAP } & \multicolumn{2}{c|}{ MCA } \\
\cline { 2 - 7 } & Rosemary & Oregano & Rosemary & Oregano & Rosemary & Oregano \\
\hline $100 p p m$ & $77.37 \pm 0.77^{\mathrm{d}}$ & $62.86 \pm 0.67^{\mathrm{e}}$ & $0.528 \pm 0.03^{\mathrm{a}}$ & $0.052 \pm 0.01^{\mathrm{a}}$ & $23.17 \pm 0.14^{\mathrm{a}}$ & $15.41 \pm 0.38^{\mathrm{a}}$ \\
\hline $200 \mathrm{ppm}$ & $76.54 \pm 0.35^{\mathrm{d}}$ & $60.38 \pm 0.57^{\mathrm{d}}$ & $0.861 \pm 0.07^{\mathrm{b}}$ & $0.426 \pm 0.08^{\mathrm{b}}$ & $31.28 \pm 0.78^{\mathrm{b}}$ & $22.96 \pm 0.29^{\mathrm{b}}$ \\
\hline $300 \mathrm{ppm}$ & $75.17 \pm 0.22^{\mathrm{c}}$ & $58.16 \pm 0.76^{\mathrm{c}}$ & $1.287 \pm 0.26^{\mathrm{c}}$ & $0.780 \pm 0.06^{\mathrm{c}}$ & $39.63 \pm 0.78^{\mathrm{c}}$ & $30.30 \pm 1.05^{\mathrm{c}}$ \\
\hline $400 \mathrm{ppm}$ & $73.18 \pm 0.72^{\mathrm{b}}$ & $56.03 \pm 0.38^{\mathrm{b}}$ & $1.849 \pm 0.06^{\mathrm{d}}$ & $0.990 \pm 0.01^{\mathrm{d}}$ & $44.40 \pm 1.83^{\mathrm{d}}$ & $34.37 \pm 0.97^{\mathrm{d}}$ \\
\hline $500 \mathrm{ppm}$ & $69.92 \pm 0.65^{\mathrm{a}}$ & $54.01 \pm 0.81^{\mathrm{a}}$ & $2.162 \pm 0.06^{\mathrm{e}}$ & $1.379 \pm 0.04^{\mathrm{e}}$ & $50.28 \pm 0.93^{\mathrm{e}}$ & $39.16 \pm 0.41^{\mathrm{e}}$ \\
\hline BHT(200 ppm) & $82.69 \pm 0.46$ & $82.69 \pm 0.46$ & $1.282 \pm 0.06$ & $1.282 \pm 0.06$ & - & - \\
\hline EDTA(1.0mm) & - & - & - & - & $85.65 \pm 0.45$ & $85.65 \pm 0.45$ \\
\hline
\end{tabular}

DPPH- Diphenyl-1 picrylhydrazyl: FRAP-Ferric reducing power assay:

MCA-metal chelating activity

*Each value is represented by the mean $\pm S D$ of $n=3$

${ }^{\text {abcd }}$ Indicate significant difference among treatments $(p<0.05)$

Table.2 Antimicrobial activity of Rosemary and Oregano extracts

\begin{tabular}{|l|l|l|l|}
\hline \multirow{2}{*}{ Microorganisms } & \multicolumn{3}{|l|}{ Zone of inhibition in mm } \\
\cline { 2 - 4 } & Rosemary & Oregano & Ampicillin \\
\hline S. aureus & $19.56 \pm 1.23$ & $15.37 \pm 0.59$ & $38.16 \pm 0.83$ \\
\hline B.subtilis & $18.49 \pm 0.34$ & $15.69 \pm 0.28$ & $32.56 \pm 1.56$ \\
\hline P.fluorescens & $11.03 \pm 0.89$ & $9.05 \pm 0.14$ & $30.75 \pm 0.12$ \\
\hline S.typium & $20.72 \pm 0.43$ & $11.09 \pm 0.71$ & $33.26 \pm 0.51$ \\
\hline E.coli & $10.37 \pm 0.03$ & $12.03 \pm 0.37$ & $24.08 \pm 0.86$ \\
\hline
\end{tabular}

The FRAP of rosemary and oregano were compared with reference standard BHT at a concentration of $200 \mathrm{mg} / \mathrm{L}$ (Table 1). The Ferric reducing antioxidant power of both rosemary and oregano extracts increased with increasing concentration $(\mathrm{p}<0.05)$. The ascending order of FRAP of the compounds were as follows: Rosemary > Oregano. Results shows BHT was 1.283 Abs at 200 $\mathrm{mg} / \mathrm{L}$. whereas, rosemary and oregano showed highest ferric reducing power of 2.162 and $1.379 \mathrm{Abs}$ respectively at 500 $\mu \mathrm{g} / \mathrm{mL}$. Increase in absorbance of the reaction mixture at $700 \mathrm{~nm}$ indicates an increase in reducing power. Rosemary and Oregano extracts were compared with reference standard BHT at a concentration of $200 \mathrm{mg} / \mathrm{L}$. The synthetic antioxidant BHT showed maximum absorbance of 1.283 Abs at $200 \mathrm{mg} / \mathrm{L}$ whereas rosemary and oregano extracts showed ferric reducing capability of 2.162 and $1.379 \mathrm{Abs}$ respectively at $500 \mathrm{mg} / \mathrm{L}$. Fernandes et al., (2016) reported that ferric reducing ability of rosemary and oregano extracts were $361.57 \pm 33.72$ and $472.32 \pm 15.96$ respectively. The results were not in agreement with findings of Shan et al., (2005) who noticed that oregano extracts $(1.01 \mathrm{mmol}$ trolox/g dw) showed higher ferric reducing antioxidant power compared with that of rosemary extracts $(0.38 \mathrm{mmol}$ trolox/g dw).

\section{Metal chelating activity of rosemary and oregano extracts}

Metal chelating activity is used to evaluate transition metal ions, especially $\mathrm{Fe}^{2+}$ and $\mathrm{Cu}^{2+}$. It is complex formation between ferrozine and $\mathrm{Fe}^{2+}$. This can be disturbed by the presence of other complexing agents 
which cause a decrease in the red colour intensity of complexes. The metal chelating activity was compared with synthetic metal chelator (EDTA) at $1.0 \mathrm{mM}$. The results of present study showed that although both the compounds were less efficient than commercial metal chelator (EDTA), rosemary extract had higher metal chelating activity than oregano extract $(\mathrm{P}<0.05)$. The maximum metal chelating activity of rosemary and oregano were seen at $500 \mathrm{mg} / \mathrm{L}$ which was $50.28 \%$ and $39.16 \%$ whereas EDTA at 1.0 $\mathrm{mM}$ showed $85.65 \%$ (Table 1). The metal chelating ability of both the compounds (rosemary and oregano extracts) was very less at lower concentrations but increased with increasing the concentration. The results were in agreement with the findings of Zhang et al., (2016) who reported that metal chelating activity of rosemary and clove was 0.41 and $0.60 \mathrm{mg} / \mathrm{ml}$ respectively. The metal chelation activity of rosemary extract was checked by According to El-Beltagi and Badawi, (2013) the percentages of metal scavenging capacity tested methanol extracts of rosemary and EDTA at $200 \mu \mathrm{g} / \mathrm{ml}$ was found to be 38.31 and $51.21 \%$ respectively. Bejaoui et al., (2013) reported that the substantial metal chelating capacity of methnolic extract, ethanolic extract and water extract from Origanum vulgare glandulosum were 76.98 , 48.95 and $31.68 \%$ respectively.

\section{In vitro antimicrobial activity of rosemary and oregano extracts}

The antimicrobial activity of rosemary and oregano were checked at $5 \mathrm{mg} / \mathrm{ml}$ and the results are shown in Table 2. The antimicrobial activity of rosemary and oregano were seen at $5 \mathrm{mg} / \mathrm{ml}$ with ampicillin as positive control at concentration of 1.0 $\mathrm{mg} / \mathrm{ml}$. It was observed that rosemary and oregano were potentially active against gram +ve bacteria Staphylococcus aureus and Bacillus subtilis whereas, it showed smaller zones of inhibition against gram -ve bacteria. In the present study, the maximum zone of inhibition was seen against Salmonella typhium whereas gram positive bacteria showed minimum zone of inhibition. The present results of the study can be compared with the findings of Zhang et al., (2016) who had investigated antimicrobial activity of rosemary at 5,10,20, $40 \mathrm{mg} / \mathrm{ml}$ concentration against E. coli and Pseudomonas fluorescens. The zone of inhibition was found to be 12.13, 13.84, 16.81, 17.54 for E. coli and 9.40, 11.45, 13.05 and 17.73 for Pseudomonas fluorescens at $5, \quad 10,20,40 \mathrm{mg} / \mathrm{ml}$ concentration respectively. Seydim and Sarikus (2007) reported that oregano was tested against E. coli, Staphylococcus and Salmonella enteritidis and the zone of inhibition were found to be 777.72, 957.25 and $883.34 \mathrm{~mm}^{2}$ respectively at $4 \%$ concentration. The higher antimicrobial activity of rosemary and oregano may be presence of core compounds like Thymol and Carvacrol which might play an important role in their antimicrobial activity. Most antimicrobial phytochemicals in herbs and spices consist of substituted phenolic rings (Lai and Roy, 2004). The $\mathrm{OH}$ groups in phenolic compounds were thought to be related to their microbial inhibitory action. There is also evidence that compounds with increasing number of $\mathrm{OH}$ groups in the compound exhibits greater toxicity to microbes (Fig. 1).

The consumers demand for natural products, free of synthetic additives. Therefore the utilization of natural plant extracts, their mixtures, isolates and concentrates antioxidant effect can improve the quality and safety of food. From the results it was observed that rosemary extract has shown highest antioxidant and antimicrobial activity compared to the oregano extract. The results of the present study indicate that, rosemary extract had highest antioxidant and 
antimicrobial activity compared to the oregano extract. The rosemary extract showed more or less similar result obtained by using synthetic antioxidant and antimicrobial compounds. Hence, it can be concluded that rosemary extract can replace synthetic antioxidant and antimicrobial compounds. Therefore it can be recommended to reduce the synthetic usage by increase the natural antioxidant and antimicrobial compounds.

\section{Acknowledgment}

The authors would like to thank the Vice Chancellor of Sri Venkateswara Veterinary University (SVVU), Tirupati, Dean of Fishery Science, SVVU, Tirupati and Associate Dean, College of Fishery science, SVVU, Muthukur for providing facility and support.

\section{References}

Bauer, A.W., Kirby, W.M.M. and Sherris, J.C. 1966. Antibiotic susceptibility testing by a standardized single disk method. American Journal of Clinical Pathology, 45:493-496.

Béjaoui, A., Chaabane, H., Jemli, M., Boulila, A. and Boussaid, M. 2013. Essential oil composition and antibacterial activity of Origanum vulgare subsp. glandulosum at different phenological stages. Journal of Medicinal Food, 16(12):1115-1120.

Bendini, A., Toschi, T. G. and Lercker, G. 2002. Antioxidant activity of oregano (Origanum vulgare L.) leaves. Italian Journal of Food Science, 14(1):17-24.

Boyer, R.F. and Mccleary, C.J. 1987. Superoxide ion as a primary reductant in ascorbate-mediated ferritin iron release. Free Radical Biology and Medicine, 3:389-395.

Dornan, H.J.D., Kosar, M., Kahlos, K., Holm, Y. and Hiltunen, R. 2003. Antioxidant properties and composition of aqueous extracts from Mentha species, hybrids, varieties, and cultivars. Journal of Agricultural and Food Chemistry, 51: 4563-4569.

El-Beltagi, H. S. and Badawi, M. H. 2013. Comparison of antioxidant and antimicrobial properties for Ginkgo biloba and rosemary (Rosmarinus officinalis L.) from Egypt. Notulae Botanicae Horti Agrobotanici ClujNapoca, 41(1):126.

Fernandes, R. P. P., Trindade, M. A., Tonin, F. G., Lima, C. G., Pugine, S. M. P., Munekata, P. E. S. and de Melo, M. P. 2016. Evaluation of antioxidant capacity of 13 plant extracts by three different methods: cluster analyses applied for selection of the natural extracts with higher antioxidant capacity to replace synthetic antioxidant in lamb burgers. Journal of Food Science and Technology, 53(1):451460.

Hendel, N., Larous, L. and Belbey, L. 2016. Antioxidant activity of rosemary (Rosmarinus officinalis) and its in vitro inhibitory effect on Penicillium digitatum. International Food Research Journal, 23(4):1725-1732.

Hernandez, E., Ponce-Alquicira, E., Jaramillo-Flores, M.E. and Guerrerolegarret, I. 2009. Antioxidant effect of rosemary (Rosmarinus officinalis L.) and oregano (Origanum vulgare L.) extracts on TBARS and colour of model raw pork batters. Meat Science, 81:410417.

Khanum, H., Ramalakshmi, K., Srinivas, P. and Borse, B.B. 2011. Synergistic antioxidant action of Oregano, Ajowan and Borage extracts. Journal of Food Nutrition Science. 2:387-392

Krishnaiah, D., Sarbatly, R. and Nithyanandam, R. 2011. A review of the antioxidant potential of medicinal plant species. Food and Bioproducts Processing, 89(3):217-233 
Lai, P. K. and Roy, J. 2004. Antimicrobial and chemopreventive properties of herbs and spices. Current Medicinal chemistry, 11 (11):1451-1460.

Loliger, J. 1989. Natural antioxidants for the stabilization of foods. In: Min, D.B., Smouse, T.H., (Eds.), Flavor Chemistry of Lipid Foods. American Oil Chemists' Society, Champaign. Pp. 302-325.

Lugemwa, F. N., Snyder, A. L. and Shaikh, K. 2013. Determination of radical scavenging activity and total phenols of wine and spices: A randomized study. Antioxidants, 2: 110-121.

Muchuweti, M., Kativu, E., Mupure, C.H., Chidewe, C., Ndhlala, A. R. and Benhura, M.A.N. 2007. Phenolic composition and antioxidant properties of some spices. American Journal of Food Technology, 2 (5):414-420.

Nair, R. and Chanda, S. 2005. Anticandidal activity of Punica granatum exhibited in different solvents. Pharmaceutical Biology, 43:21-25.

Nakatani, N. 2003. Biologically functional constituents of spices and herbs. Journal of Japanese Society. Nutritional and Food Science, 56(6):389- 395

Nuutila, A. M., Puupponen-Pimia, R., Aarni, M. and Oksman Caldentey, K. M. 2003. Comparision of antioxidant activities of onion and garlic extracts by inhibition of lipid peroxidation and radical scavenging activity. Food Chemistry, 81:485-493.

Oyaizu, M. 1986. Studies on product browning reaction: antioxidant activity of products of browning reaction prepared from glucosamine. Journal of Nutrition, 44:307-315.

Rac, M. and Ostric, B. 1955. les properties of antioxygeneus du romarin rev fr corps Gras 2, 796-803.

Seydim, A. C. and Sarikus, G. 2007. Antimicrobial activity of wheyprotein based edible films incorporated with oregano, rosemary and garlic essential oils. Food Research International, 39(5):639-644.

Shan, B., Cai, Y. Z., Sun, M. and Corke, H. 2005. Antioxidant capacity of 26 spice extracts and characterization of their phenolic constituents. Journal of Agricultural and Food Chemistry, 53(20):7749-7759.

Tironi, V., Tomas, M. and Anon, M. 2009. Lipid and protein changes in chilled sea salmon (Pseudopercis semifasciata): effect of previous rosemary extract (Rosmarinus offcinalis) application. International Journal of Food Science \& Technology, 44:1254-1262.

Yen, G. C. and Wu, J. Y. 1999. Antioxidant and radical scavenging properties of extracts from Ganoderma tsugae. Food Chemistry, 65(3):375-379.

Zhang, H., Wu, J. and Guo, X. 2016. Effects of antimicrobial and antioxidant activities of spice extracts on raw chicken meat quality. Food Science and Human Wellness, 5 (1):39-48.

\section{How to cite this article:}

Kumuda, M., K. Dhanapal, K. Sravani, K. Madhavi, Faisal Rashid Sofi and Praveen Kumar, G. 2017. Studies on the Antioxidant and Antimicrobial Properties of Rosemary (Rosemarinus officinalis) and Oregano (Origanum vulgare) Extracts. Int.J.Curr.Microbiol.App.Sci. 6(12): 3253-3261. doi: https://doi.org/10.20546/ijcmas.2017.612.378 